\title{
ПЕРСОНАЛИИ
}

УДК 811.161 .1 .374

\section{О.И. Блинова}

\section{ВИКТОР АСТАФЬЕВ О СЛОВЕ И СЛОВАРЯХ ${ }^{1}$}

Автор статьи, опираясь на широкий круг источников (художественную прозу, очерки, письма Виктора Астафьева и личные встречи с ним) раскрывает читателю взгляды великого писателя на СЛОВО и СЛОВАРИ, на восприятие и оченку слова, разговорного, бытового и художественного поэтического.

Ключевые слова: слово, роль слова, поэтическое слово, словарь.

Настало время ценить... самое дорогое, что у нас еще есть, - наше родное слово основу основ нашей жизни.

Виктор Астафьев

Дорогие друзья - Томичи!

Дорогая О.И. Блинова!

Лёгкая у вас рука у всех и добрый характер. «Словарь» вы мне прислали к самому разу - я работаю над второй книгой романа $и$ ваш труд очень мне поможет, да и уже помогает в работе. Живу я сейчас и работаю в деревне, всего из города не захватишь, и вот как вы ловко мне помогли.

Спасибо, спасибо!

Рад, что несмотря на все неурядицы научная работа продолжается и вы делаете Богом назначенное дело. Низко кланяюсь всему вашему коллективу, работающему над словарем. Не забывайте меня, а я с чувством благодарности думаю о вас и желаю вам доброго здоровья, исполнения всех ваших желаний и творческих поисков.

Храни вас Бог!

Baи Acтафьев.

21 июня 1993 г. С. Овсянка [1. С. 444].

${ }^{1}$ Под этим названием предлагается читателю расширенный вариант ранее опубликованной статьи автора в кн.: Астафьевские чтения (ноябрь 2008). Время «Весёлого солдата»: Ценности послевоенного общества и их осмысление в современной России. Пермь, 2009. C. 47-61.

${ }^{2}$ Имеется в виду «Полный словарь сибирского говора» (ред. О.И. Блинова. Томск, 1992. T. 1).

${ }^{3}$ Роман «Прокляты и убиты». 
Содержание письма, с которого началась наша переписка, и предваряющего статью эпиграфа говорят не только о трепетном отношении писателя к словарному труду, но и дают высшую оценку СЛОВУ: «ОСНОВЕ ОСНОВ нашей жизни».

В связи с этим уместно напомнить слова А.С. Пушкина: «Всякая строчка великого писателя становится драгоценной для потомства». Они применимы ко всему, что оставил потомкам Астафьев, - к строкам его художественных произведений.

Предваряющий статью эпиграф явился толчком к постановке проблемы астафьевского слова - главного средства его творчества, исследование которого позволило бы дать хотя бы частичный ответ на ряд вопросов: каковы истоки астафьевского слова, оценка и отношение к слову, роль слова в обществе и в литературных произведениях и многие-многие другие, системное изучение которых по тем или иным направлениям, проблемам, аспектам приблизило бы к постижению «многогранной личности великого поэта России, писавшего прозой» [2. С. 224].

В комментарии к двенадцатому тому собрания сочинений Астафьев с сожалением отметил: «Вот составил книгу и обнаружил, как мало писал и беседовал я о нашем русском языке... совсем мало писал о театре и музыке, а ведь жил ими, укреплялся ими, да и существовал, обогащаясь духовно» [3. Т. 12. С. 605].

Ответы на поставленные вопросы об астафьевском слове даст его богатое художественное наследие, а высказывания писателя о слове придется собирать по крупицам в ранее названных источниках. Редкое исключение в этом плане представляет очерк Астафьева «Очарованные словом» [3. Т. 12. С. 83-93], составивший основной источник для настоящей статьи.

Поводом к появлению очерка стала просьба автора статьи, обращенная к писателю, принять участие в общественном обсуждении работы диалектологов Томского университета, выдвинутой на соискание Государственной премии РФ 1997 г. Работа «Комплексное исследование русских говоров Среднего Приобья (1964-1995 гг.)» включала ряд среднеобских словарей, с которыми В. Астафьев был хорошо знаком. Очерк был впервые опубликован в 1997 г. в газете «Российские вести», перепечатан в журнале «Студенческий меридиан», а затем включен в собрание сочинений писателя. 
Материалы очерка, огромное литературное наследие писателя позволяют составить представление о том, что есть для Астафьева СЛОВО - слово обыденной речи и слово художественное - и как он оценивал роль СЛОВАРЕЙ.

$$
* * *
$$

Каждый человек начинается с детства. Детство Вити Астафьева прошло в селе Овсянка Красноярского края, в окружении сибирской природы, на берегу могучего Енисея с его скалистыми берегами. Обладая уникальной памятью, мальчик вынес из детства знание образной сибирской речи, впитал крестьянскую материальную и духовную культуру, усвоил трепетное отношение, любовь к природе. В детстве произошла знаковая для будущего мастера слова встреча с учителем-словесником Игнатием Дмитриевичем Рождественским, пробудившим и воспитавшим в мальчике дар «очарования словом».

«B тридиатых годах, - вспоминает писатель, - в далекой заполярной игарской школе появился высокий чернявый парень в очках. $<\ldots>$ Он начал нам рассказывать о русском языке, о его красоте, богатстве и величии. Нам и прежде рассказывали обо всем этом, но так тягуче и скучно... что в наши удалые головы ничего не проникало и сердияа не трогало.

A этот учитель говорил, все больше распаляясь, читал стихи, приводил пословиць и поговорки, да одну другой складнее, и, дойдя до слова "яр", усидеть на месте не мог, метался по классу, горячо жестикулировал... и выходило, что слово "яр" есть самоглавнейшее и красивейшее слово на свете и в русском языке, ведь и название городов - Ярославль, Красноярск - не могло обойтись без "яра", и берег обрывистый зовется яр, да и само солнце звалось Ярило, яровое поле - ржаное поле, яровица, ярииа, которую весной сеют, ярый, яростный человек... а ярка, с которой шерсть стригут? <...> Поняли мы: без слова "яр" не то что ни дыхнуть, ни охнуть, но и вообще дальше жить невозможно...

"Очарование словом" - не сразу, не вдруг определил я чувство, овладевшее нами, учениками школь...» [3. Т. 12. С. 83-84].

Это чувство ляжет в основу эстетического кредо писателя, воплотившись в опоэтизацию слова обыденного и художественного [4-6]. 
Характеризуя состояние русского языка второй половины XX в., Астафьев с болью говорит о таких уродливых явлениях, как безудержная жаргонизация и криминализация устной речи, бездумное заимствование иностранных слов («инаугурация» и др.), втаптывание в грязь исконных слов языка (например, слова «блин»), бедный запас слов. «Ox, как больно, порой трагично народу нашему обходились всяческая забывчивость и предательство впитанного с молоком матери родного языка» [3. Т. 12. С. 89].

«Тюремно-лагерно-ссыльному сленгу» Астафьев противопоставляет родной язык, родное слово, не раз обращаясь к речи сибиряков.

Астафьев подчеркивает роль сибирского диалекта как источника, питающего литературную речь: «Mы ведь говорим много, неинтересно, длинно и путано оттого, - сокрушается писатель, - что не знаем своего родного языка, не умеем, не научены им толком пользоваться, в то время как сибирские старообрядиь, не подверженные новомодным влияниям, сохранили чистейший, образный русский язык»» [3. Т. 12. С. 87].

Сибирский диалект для писателя был символом малой родины: «...землячество объединяло всех сибиряков и на фронте. В толчее армейской, в окопном скопище по говору узнавали чалдоны друг друга и так светло радовались этому - язык объединял нас, роднил... То же и в литературе. Сергей Павлович Зальгин, Николай Николаевич Яновский, Сергей Сартаков, Владимир Чивилихин, тот же Виль Липатов, Василий Фёдоров, Аскольд Якубовский, Ефим Пермитин и многие другие, оказавшись жителями столищы, за счастье почитали встретиться, пообщаться, потолковать о Сибири "по-сибирски"» [3. Т. 12. С. 90].

В творчестве Виктора Петровича сибирской деревне посвящено значительное число повестей и рассказов. С этим связано его широкое обращение к сибирской речи как средству художественной изобразительности. В этом он находил поддержку у читателей, литературных критиков, редакторов.

Он вспоминает о словах главного редактора Пермского издательства Б.Н. Назаровского, долго жившего в Сибири, который сказал: «Виктор Петрович, пой свою родную Сибирь: не подделывайся под Урал, не надо, не получится, язык-то один, русский, но произношение, но характер разные» [3. Т. 12. С. 90]. 
Писатель осознавал, что диалектная лексика трудна для перевода на другие языки. Он отмечал, что во Франции, Чехословакии, Польше и ещё в ряде стран переводили «Царь-рыбу», мучаясь с переводом как самого витиеватого, непереводимого названия. В одном из интервью по поводу перевода повести «Последний поклон» на английский язык под названием «Кивок головы» он заметил: «Думаю, что мои труднопереводимые названия книг и язык, изобилующий местной речью... переводить буквально нельзя» [7].

Трепетно и с любовью относился Виктор Петрович к сибирским диалектным словарям. С большинством из них он был знаком, некоторые использовал как дополнительный источник в своей работе. Вот ряд его определений, относящихся к словарям: уникальный, бесиенный труд; хранители отечественной культуры; святое, патриотическое, нужное народу дело; благородное, творческое дело; словесные клады [3. Т. 12. C. 90-92].

Писатель, выражая признательность за присылаемые ему словари, высказал пожелание: «...комплименты, которыми меня осыпают критики и читатели за знание родного языка, надо бы адресовать на кафедры русского языка Томского университета и в Красноярский пединститут» [3. Т. 12. С. 90]. Следует заметить, что сибирские словари служили лишь дополнительным подспорьем в работе писателя, прекрасно знавшего сибирский диалект.

Хочу привести еще два высказывания В. Астафьева. Первое, уже приводившееся, но без сокращений: «Настало время ценить и поощрять тех, кто помогает сохранить и вернуть нам самое дорогое, что у нас еще есть, - наше родное слово, основу основ нашей жизни» [3. Т. 12. С. 91]. И второе, уже цитировавшееся: «Когда такие люди... стерегут русское слово, быть ему живу и России воскреснуть. Живо слово - жив народ» [3. Т. 12. С. 91]. Комментарии, как говорится, излишни.

Виктор Петрович не оставил нам работ о том, каким он видел художественное слово. Об этом красноречиво говорят его творчество, его размышления, разбросанные в комментариях к отдельным томам собрания сочинений, встречающиеся в его интервью, в тексте повестей и рассказов.

Одна из ярких особенностей идиостиля Астафьева, как уже отмечалось, привлечение в художественные произведения значитель- 
ного диалектного пласта. Диалектный пласт в прозе Астафьева, словно пласт сибирской земли, - это одно из языковых средств живописания Сибири, ее природы: цветов и трав, деревьев и кустарников, рек и ручьев, возвышенностей и низин, ее людей, их быта, промыслов, обрядов и обычаев.

Следуя лучшим традициям русской литературы, Астафьев идет в эстетическом освоении диалектного пласта дальше, расширяя его роль и художественные функции. Диалектизмы в астафьевской прозе не экзотика, не случайные вкрапления в литературную речь, а полноправные слова, которые не берутся в кавычки, крайне редко поясняются, они живут в поэтическом тексте, живут как единственно возможные, единственно необходимые для воплощения художественного замысла: "Дом мальчика стоял лицуом к реке, зависая окнами и завалинкой над подмытым крутоярьем. заросшим шептун-травой, чернобыльником, всюду пролезающей жалиией» [3. Т. 8. C. 9].

В традициях русской литературы функциональные характеристики диалектных элементов укладываются в следующий набор: диалектизмы как средство реалистического изображения крестьянской жизни; средство создания местного колорита, социальноречевого портрета; средство стилизации под народную речь; реже как средство создания образности. В прозе Астафьева диалектизмы характеризуют его идиостиль: создание поэтичности, насыщенной образности, звукописи, музыкальности, мелодики и ритмики; кроме того, диалектизмы связаны с эстетическим отражением народной культуры - духовной и речевой [8. С. 178-183].

Концентрация, насыщенность художественного текста образными единицами языка - метафорами, сравнениями, антропоморфизмами - одна из ярких черт идиостиля Астафьева. В нижеприведенном тексте насыщенность диалектными словами - 6 на 6 строчек отрывка: «Тлен прошлогодней травы, закисающуих болот и умершей хвои плотно прикрывало ароматами новоцветья. На смену сыплющуимся на угреве жаркам, свернувшейся медунице слепило золотом курослепа, по оподолью кустов и каменных гряд шел в дудку дедюльник - так в здешних местах по-детски ласково называли медвежью пучку» («У золотой карги»).

Диалектное слово в прозе Астафьева может выражать не одну, а несколько фигур речи. Не однажды встречающееся на страницах его 
произведений слово «оподолье» с обыденным значением «кромка подола [платья, юбки]», овеянное фольклорной традицией, обретает метафорическое значение берегов кромки, кромки «каменного платья〉 могучей сибирской реки. Одновременно это слово вплетено в рамки приема синтаксического параллелизма, создающего ритмику отрывка: «Река одетая / в каменное платье, / украшенная / по оподолью / то тяжелыми блестками алмазов / вечной мерзлоты, / то жарким пламенем ияетов / по берегам-бечевкам, / то мысом, / вспененным пушицею, / галечными заплёсками» («Туруханская лилия»).

Диалектизмы выполняют важную и «ответственную» функцию функцию заголовка, наполненного образно-символическим смыслом. Один из замечательных астафьевских циклов, объединяющих около двухсот авторских «собеседований с собой и с людьми», назван диалектным словом «Затеси». Семантику его писатель объясняет в первой из семи тетрадей цикла «Падение листа», в рассказе «Поход по метам»: «Затесь - сама по себе вещь древняя и всем ведомая - это стёс, сделанный на дереве топором или другим каким острым предметом... белеющая на стволе дерева мета была видна издалека, и ходили по тайге от меты к мете...

В разных концах России название мет варьируется: «зарубы», «затёсиныл», «затёски», «затёсыl», по-сибирски - «затеси» <... Название таёжных мет врубилось в мою память... прочно и... надолго» («Поход по метам») [3. Т. 7. С. 8].

Обретя всероссийскую известность, слово «затеси» наполнилось глубоким философским смыслом: это не только мета на дереве, но и, по выражению писателя, на «древе жизни», «зарубки на сердце о нашей с вами жизни, о прошлом, о войне».

Диалектным словом названы и другие короткие рассказы писателя: «Хлебозары» (цикл «Падение листа»), «С кусоцкём», «Чужая обутка» (цикл «Игра»), «Бритовка» (цикл «Рукою согретый хлеб»), «У золотой карги», «Туруханская лилия» (повесть «Царь-рыба»), «Заберега» («Последний поклон»), повесть «Стародуб».

Особого внимания заслуживает название повести «Стародуб». В комментарии ко второму тому собрания сочинений, куда включена повесть, В. Астафьев пишет о том «наваждении», той магии, которая исходит от цветка: «...цветок стародуб, как первая любовь, не расиветает на бумаге, сиял в моём сердие и требовал или, может, нашептывал мне о себе во сне и наяву, чтоб я никогда не забывал о 
нём и о родине его - Сибири, чтобы непременно рассказал людям о лесных чудесах и таинствах, поделился тем богатством, которое цвело в моей душе, согревая ее, наполняя светом любви ко всему сущему и красивому, подаренному Создателем нам, грешным людям» [3. T. 2. C. 488].

В начале повести устами охотника-старообрядца раскрывается история названия цветка стародуб (от дуба), который в ходе развития сюжета обретает разные символические значения - от символа стойкости до символов родины, несбывшейся любви к женщине, добра и любви к людям. Слово «стародуб» наделяется статусом ключевого и выполняет в повести функцию обрамления.

В. Астафьев чуток к внутренней форме слова, особенно диалектного, и нередко прибегает к использованию приёма оживления его внутренней формы, что неизбежно ведёт к созданию языковой образности.

Так, сибирское название купальниц жарки с огненным цветом их лепестков (за что в среднеобских говорах они получили название огоньки) писатель сопоставляет с жаркими углями, используя мотивационную связь: "Дотлела зорька. Темнота обступила костер. Вокруг него виднеются бледные пятна цветов. Эти жёлтые ияветы на Урале и в Подмосковье называют купавками, а в Сибири - жарками, потому что в Сибири они огненно-яркого ивета и светятся в траве, что жаркие угли» («Ах ты, ноченька»). В другом случае название жарки он оживляет с помощью также диалектного слова отгар - «то, что отгорело»: «Купьри и морковники силились пойти в дудку, жарки тут, на солнцепеке, уже сорили по ветру отгаром лепестков..». («Монах в новых штанах»).

Избранная тема и в малой степени не может быть раскрыта, освещена в рамках журнальной статьи. За её пределами остается многое из высказанного великим художником слова о слове при его жизни: в его романах, повестях, рассказах и «затесях», в письмах и автографах на подаренных им книгах, в выступлениях на конференциях и «литературных встречах в русской провинции», во время встреч с томскими диалектологами - «словарниками», как он нас называл. В какой-то степени это может быть восполнено в разных публикациях, часть которых предлагается в конце статьи и в цитируемых ссылках списка литературы. 
Виктор Петрович воспринимал слово не только как звучащесмысловую сущность, призванную обслуживать нужды общения в различных сферах - коммуникативной, экспрессивной, эстетической и др. Он был убеждён, что слово и выражаемая им мысль обладают «материальной, вещественной» силой, способной к самореализации. И я дважды была тому свидетелем.

Первый раз - когда наша делегация томских диалектологов, участников Международного съезда русистов в Красноярске, была приглашена в гости к Астафьевым (случилось это памятное событие 2 октября 1997 г.). Мы были покорены радушием хозяев. Встреча раскрыла простоту и человечность Виктора Петровича, богатый духовный мир, широчайшую эрудицию. Он делился с нами воспоминаниями о поэтах и прозаиках, которых он лично знал, - о Н. Рубцове, В. Белове, В. Быкове и др., читал свои рассказы, познакомил с богатейшей домашней библиотекой, с зарубежными изданиями своих книг, переведённых на разные языки мира. Он пел с нами и для нас песни, блистал остроумием, подарил всем нам по экземпляру журнала «Студенческий меридиан» с автографом (в журнале был очерк «Очарованные словом»). Узнав, что я увлекаюсь рыбалкой, подарил мне свою знаменитую «Царь-рыбу» с шутливым автографом: «Ольге Иосифовне Блиновой с любовью мою «Царь-рыбу» на уху». Я так была переполнена счастьем от той встречи, что сказала Виктору Петровичу о том, что на этом вечере можно бы поставить мою жизненную точку. Виктор Петрович буквально обрушился на меня: «Никогда так не говорите: слова материальны!»

Второй раз - в феврале 1999 г. На пресс-конференции в Томском университете Виктор Петрович в ответе на заданный вопрос «Что для вас смерть в прошлом и сейчас» вернулся к утверждению о материальном характере мыслей и выражающих их слов: «O смерти говорите осторожно, никогда не примеряйте её к себе, - ответил он. - Мысль о смерти вещественна. Будьте молодыми и жизнерадостными. Грязь в свою душу не пускайте и дурные мысли в свою голову не берите».

Последняя встреча с Виктором Петровичем произошла в феврале 1999 г. По моему вторичному приглашению он приехал в Томск, предварительно высказав два пожелания: встретиться с томскими «словарниками» и студентами Томского университета, который он боготворил и считал «святым местом». 
Можно представить, с каким нетерпением мы ждали этого визита, чтобы поблагодарить Виктора Петровича за годы дружбы, поддержки, высокой оценки нашего и не только нелегкого словарного труда, за присланные в дар книги. Волнующая встреча диалектологов с дорогим и желанным гостем состоялась на кафедре русского языка. Длилась она более пяти часов, пролетевших незаметно, и произвела неизгладимое впечатление: Виктор Петрович познакомился с диалектными картотеками, собранными в течение полувека, с основателями и представителями Томской диалектологической школы, рассказывал истории из своей жизни, много шутил, смеялся, слушал в исполнении диалектологов образцы сибирской речи, о том, как собираются народные слова. В завершение встречи он прочел вслух по нашей просьбе три своих рассказа.

На следующий день в конференц-зале университета Виктор Петрович провел блистательную пресс-конференцию для студентов и преподавателей, ответив на многочисленные вопросы. На прощальном ужине у нас в доме он говорил о том, что осталось в его душе после пребывания в Томске. Сердечный приём у диалектологов кафедры русского языка ТГУ, волнующая пресс-конференция, беседа в ректорате университета, экскурсии по Томску и многое другое воодушевили его. На перроне вокзала Томск-1 мы с сыном провожали Виктора Петровича. Он обещал непременно посетить Томск, еще раз, добавив: «Пока Марья жива, и я жив буду. Обязательно приеду».

В центре изучения творчества Виктора Астафьева (центр открыт в Библиотеке-музее села Овсянка) есть стеллаж, на одной из полок которого стоят все среднеобские словари, присланные или привезённые томскими словарниками в дар писателю. Один из них - «Словарь образных слов и выражений народного говора» с посвящением: «Виктору Петровичу Астафьеву, ценителю и знатоку народного слова» - вышел в свет 29 ноября 2001 г., в день его кончины.

Причисленность к лику очарованных словом Виктор Петрович доказал своим творчеством, всей своей жизнью.

\section{Лumepamypa}

1. Томские письма Виктора Астафьева / публ., коммент. и примеч. О.И. Блиновой // Юбилейные Астафьевские чтения «Писатель и его эпоха», 28-30 апреля 2009 г. - Красноярск, 2009. Вып. 5. - С. 441-456. 
2. Солнцев Р. Астафьев // «И открой в себе память...»: Материалы к биографии В.П. Астафьева. - Красноярск, 2005. - С. 218-234.

3. Астафьев В.П. Собрание сочинений: в 15 т. - Красноярск : Офсет, 1998. T. 12.

4. Бобкова Ю.Г. Живое слово народной речи в художественном стиле В.П. Астафьева // 1-е Астафьевские чтения, 17-18 мая 2002 г. - Пермь, 2003. - С. $37-$ 38 .

5. Подюков И.А. Эстетика народной речи в поэтике В.П. Астафьева // 1-е Астафьевские чтения, 17-18 мая 2002 г. - Пермь, 2003. - С. 7-14.

6. Блинова О.И. Очарованный словом: Заметки об идиостиле Виктора Астафьева // Феномен В.П. Астафьева в общественно-культурной и литературной жизни конца XX века: сб. материалов 1-й Междунар. науч. конф., посвящ. творчеству В.П. Астафьева, 7-9 сентября 2004 г. - Красноярск, 2005. - С. 116-118.

7. Шлёнская Г. Взаболь. Отрывки воспоминаний // «И открой в себе память...»: Материалы к биографии В.П. Астафьева. - Красноярск, 2005. - С. 254-290.

\section{VIKTOR ASTAFIEV ON THE WORD AND DICTIONARIES.}

Tomsk State University Journal of Lexicography, 2014, 1 (5), pp. 108-119.

Blinova Olga I., Tomsk State University (Tomsk, Russian Federation). E-mail: blinova_11@mail.ru

Keywords: word, role of word, poetic word, dictionary.

Drawing on a wide range of sources, among which are fiction, essays, letters and personal meetings with Viktor Astafiev, the author tells the reader what this great writer thought about the WORD and DICTIONARIES, the perception and evaluation of the colloquial, everyday and artistic, poetic word.

The article describes Astafiev's childhood memories about his meeting with the teacher who revealed to the student the greatness of the WORD, its poetry and value. The writer refers to the phenomenon of word poetization as an enchantment, as he would later write in his essay "Enchanted with the word". In this essay he tells about those who collect and compiles dictionaries that are "the keystone of our life". Full of pain, he describes the status of the Russian language in the second half of the 20th century, speaking about its vulgarization and emphasizing the life-giving role of Siberian dialects for the development of the literary language.

With tenderness and love Astafiev treated the dictionaries of Siberian dialects that he used in his works. According to the writer, dialects form "the Siberian land stratum".

Astafiev supported the State Prize nomination of the series of dialect dictionaries compiled by Tomsk researchers. He found the arguments to address the Council on State Prizes when the nomination was under discussion, after which Tomsk researchers rose to the first place from the 4 th in the nomination list of a hundred contenders.

The article draws attention to the variety of functions dialectisms perform in Astafiev's works. The writer continues the tradition of the Russian literature in attracting the following functional characteristics of dialectal elements: dialectisms as a means of realistic depiction of rural life, of creating local color or sociolinguistic portraits; of folk speech imitation and, sometimes, of creating imagery. He goes further by expanding the role of folk speech elements considering them as equal to the units of literary language. He uses the folk word as a means of artistic expression. 
Astafiev emphasized the untranslatability of the folk word into foreign languages.

In the final part of the article the author tells about the meetings the writer had with Tomsk dialectologists in Krasnoyarsk, in his home. Astafiev also visited Tomsk and was invited to the Russian Language Department of Tomsk State University, where he communicated with Tomsk dialectologists and showed was genuine interest to the card indices of dialects and dialectal texts. This meeting lasted for five hours. The next day Astafiev held the press conference for the students and professors of Tomsk State University and answered a lot of questions. Viktor Petrovich expressed a high opinion of Tomsk State University and the level of philological education demonstrated by students.

Finally, Astafiev visited the Blinovs, where he met with famous writers Vadim Maksheyev and Eduard Burmakin. He was deeply satisfied with his visit to Tomsk and gave a promise to visit Tomsk and Tomsk State University again.

The article ends with the words: "Viktor Petrovich proved his belonging to those enchanted with the WORD by all his works and the whole life".

\section{References}

1. Blinova O.I. [Tomsk letters by Viktor Astafiev: contributions, comments and notes]. Yubileynye Astaf'evskie chteniya "Pisatel' i ego epokha". [Commemorative Astafiev Readings "The writer and their era"]. Krasnoyarsk, 2009, Issue 5, pp. 441 - 456. (In Russian).

2. Solntsev R. Astaf'ev [Astafiev]. In: "I otkroy v sebe pamyat'...": Materialy $k$ biografii V.P. Astaf'eva ["And find memory within you": the biography of V.P. Astafiev]. Krasnoyarsk, 2005, pp. 218-234.

3. Astafiev V.P. Sobranie sochineniy: V 15 tomakh [Collected works: In 15 Vols.]. Krasnoyarsk, Ofset Publ., 1998. Vol. 12.

4. Bobkova Yu.G. [The Live word of vernacular speech in V.P. Astafiev's artistic style]. 1-e Astaf'evskie chteniya (17-18 maya 2002 goda) [The Fisrt Astafiev Readings (May 17-18, 2002)]. Perm, 2003, pp. 37-38. (In Russian).

5. Podyukov I.A. [Aesthetics of folk speech in V.P. Astafiev's poetics]. 1-e Astaf'evskie chteniya (17-18 maya 2002 goda) [The Fisrt Astafiev Readings (May 17-18, 2002)]. Perm, 2003, pp. 7-14. (In Russian).

6. Blinova O.I. [Enchanted with the word: Notes on Viktor Astafiev's idiostyle]. Fenomen V.P. Astaf'eva v obshchestvenno-kul'turnoy i literaturnoy zhizni kontsa XX veka: Sb. materialov 1-y Mezhdunar. nauch. konf., posvyashchennyy tvorchestvu V.P. Astaf'eva [Phenomenon of V.P. Astafiev in the socio-cultural and literary life of the late 20th century. Proc. of the 1st International Research Conference dedicated to V.P. Astafiev's oeuvre]. Krasnoyarsk, 2005, pp. 116-118. (In Russian).

7. Shlenskaya G. Vzabol'. Otryvki vospominaniy [In troth. Fragments of memories]. In: "I otkroy $v$ sebe pamyat'...": Materialy $k$ biografii V.P. Astaf'eva ["And find memory within you": the biography of V.P. Astafiev]. Krasnoyarsk, 2005, pp. 254-290. 